\title{
Ideal site for ventricular anchoring of artificial chordae in mitral regurgitation
}

\author{
Alberto Weber, MD, ${ }^{\mathrm{a}}$ Samuel Hurni, MD, ${ }^{\mathrm{a}}$ Stijn Vandenberghe, $\mathrm{PhD},{ }^{\mathrm{b}}$ Andreas Wahl, MD, ${ }^{\mathrm{c}}$ \\ Thierry Aymard, MD, ${ }^{\mathrm{a}}$ Rolf Vogel, $\mathrm{PhD}, \mathrm{MD},{ }^{\mathrm{b}, \mathrm{c}}$ and Thierry Carrel, $\mathrm{MD}^{\mathrm{a}}$
}

\begin{abstract}
Objective: Surgical treatment of mitral leaflet prolapse using artificial neochordae shows excellent outcomes. Upcoming devices attempt the same treatment in a minimally invasive way but target the left ventricular apex as an anchoring point, rather than the tip of the corresponding papillary muscle. In this study, cine cardiac magnetic resonance imaging was used to compare these 2 different anchoring positions and their dynamic relationship with the mitral leaflets.
\end{abstract}

\begin{abstract}
Methods: Eleven healthy volunteers (mean age, 31 years; 6 female; mean ejection fraction, $62 \%$ ) were examined by cardiac magnetic resonance imaging ( 3 Tesla, cine steady free precession technique with retrospective gating), whereby dedicated software enabled assessment of the physiologic distances among 3 anchoring sites (anterior papillary muscle, posterior papillary muscle, and apex) and the plane of the mitral annulus at the level of leaflet coaptation. These distances were measured in systole and diastole, and the performance of virtual neochordae was analyzed for the 3 potential anchoring sites.

Results: Length difference between systole and diastole for the 3 measured distances were $0.19 \pm 0.11 \mathrm{~cm}$ $(5.9 \% \pm 3.4 \%)$ for the anterior papillary muscle, $0.19 \pm 0.09 \mathrm{~cm}(6.7 \% \pm 3.6 \%)$ for the posterior papillary muscle, and $1.52 \pm 0.18 \mathrm{~cm}(17.8 \% \pm 2.8 \%)$ for the left ventricular apex $(P=.001)$. Virtual neochordae between the leaflet and the left ventricular apex were first adjusted in systole to achieve leaflet coaptation. Leaflet tear in diastole can only be avoided if the width of the attached leaflet is larger than the systole-diastole length difference. On the other hand, if virtual neochordae are adjusted in diastole to avoid leaflet tear, residual leaflet prolapse during systole can result. Because the systole-diastole length difference for papillary muscle anchored chordae is smaller than for apical chordae by a factor 10 , there is a strongly reduced risk of prolapse or tearing and the leaflet width is unimportant. Furthermore, if the neochordae attached to the anterior mitral leaflet uses the apex as a distal anchoring site, the angle $\alpha$ between the aortic valve plane and this mitral leaflet is significantly reduced in diastole and therefore increases the risk of systolic anterior motion.
\end{abstract}

Conclusions: Anchoring of neochordae at the papillary muscles, thereby mimicking the real anatomy, should be preferred over the left ventricular apex. Further analysis of dilated hearts and papillary muscle displacement is necessary to include the whole spectrum of pathologies. (J Thorac Cardiovasc Surg 2012;143:S78-81)

Mitral valve repair shows superior results compared with mitral valve replacement and has become the procedure of choice for the treatment of mitral regurgitation. ${ }^{1}$ With increased understanding of the heterogenic pathophysiology of mitral regurgitation, cardiac surgeons have

From the Department of Cardiovascular Surgery, ${ }^{\mathrm{a}}$ Inselspital, Bern University Hospital and University of Berne, Switzerland; ARTORG, ${ }^{\mathrm{b}}$ University of Berne, Switzerland; and Department of Cardiology, ${ }^{\mathrm{c}}$ Inselspital, Bern University Hospital and University of Berne, Switzerland.

Disclosures: Alberto Weber, Samuel Hurni, Stijn Vandenberghe, Andreas Wahl, Thierry Aymard, Rolf Vogel, and Thierry Carrel have nothing to disclose with regard to commercial support.

Presented at The American Association for Thoracic Surgery Mitral Conclave, New York, New York, May 5-6, 2011.

Received for publication May 15, 2011; revisions received Sept 16, 2011; accepted for publication Sept 26, 2011; available ahead of print Oct 31, 2011.

Address for reprints: Alberto Weber, MD, Department of Cardiovascular Surgery, Inselspital, University Hospital Bern, 3010, Bern, Switzerland (E-mail: alberto. weber@insel.ch).

$0022-5223 / \$ 36.00$

Copyright ( 12012 by The American Association for Thoracic Surgery

doi:10.1016/j.jtcvs.2011.09.031 developed various techniques that increase the likelihood of successful repair. ${ }^{2}$

Chordal replacement with expanded polytetrafluoroethylene sutures (Gore-Tex; WL Gore \& Associates, Inc, Flagstaff, Ariz) was introduced experimentally ${ }^{3}$ and clinically ${ }^{4}$ in the 1980s. Current use in clinical practice has permitted effective and safe repair of complex mitral lesions ${ }^{5,6}$ and is associated with low operative mortality and low rates of valve-related complications at long-term follow-up. ${ }^{7}$

Mitral valve repair with polytetrafluoroethylene (GoreTex) artificial chordae can also be achieved through minimally invasive approaches. ${ }^{8}$ The desire for even lessinvasive approaches has driven the development of various technologies that are now emerging in investigational studies. ${ }^{9}$

The concept of beating heart transapical insertion of artificial chordae for mitral valve repair using the NeoChord DS1000 device (NeoChord Inc, Minnetonka, Minn) has been introduced and explored in acute animal studies in 2009. The left ventricular (LV) apex is used as anchoring 


\section{Abbreviations and Acronyms \\ $\mathrm{LV} \quad=$ left ventricular \\ $\mathrm{PM}=$ papillary muscle}

point for artificial chordae. ${ }^{9}$ This technique has been applied in few human subjects, in whom the chordae length can be adjusted from the outside of the apex on the basis of color Doppler images. However, special consideration needs to be given to the number and length of neochordae to correct the prolapse. ${ }^{10}$

This study compares different anchoring sites of artificial chordae in the human left ventricle and analyzes their dynamic distance to the mitral leaflets. By means of cardiac magnetic resonance imaging, the effect of valve function in systole and diastole is estimated when a fixed length artificial chordae would be anchored to different positions.

\section{MATERIALS AND METHODS}

Of 20 healthy volunteers who underwent a complete cardiac magnetic resonance examination, 11 (mean age, 31 years; 6 female; mean LV ejection fraction, $62 \%$ ) met the requirements to guarantee repeatability of the measurements described below. All volunteers gave written, informed consent, and the local ethics committee approved these examinations.

\section{Cardiac Magnetic Resonance Imaging}

Study individuals were examined in the supine position by an experienced magnetic resonance imaging clinician using a $3 \mathrm{~T}$ (Magnetom Verio; Siemens Medical Solutions, Erlangen, Germany) whole-body clinical magnetic resonance imaging system. Cardiac synchronization was obtained from 3 electrodes placed on the left anterior hemithorax. A cine steadystate free-precession technique with retrospective gating was used. The cardiac short axis was determined from 3 scout images: midventricular axial view, cine breath-hold vertical long axis, and cine breath-hold horizontal long axis. A stack of short-axis slices covering the entire LV and RV and standard true long-axis views, comprising 4-, 3-, and 2-chamber views, were acquired in each individual during short end-expiratory breath-holds. Magnetic resonance imaging analysis was performed twice off-line in random order by 2 independent experienced observers. A dedicated workstation with commercially available software (Argus, Siemens Medical Solutions) was used to perform accurate measurements off-line in high resolution. We identified the optimal insertion point for neochordae anchoring to the mitral valve leaflet edge at the coaptation level of A2/P2 leaflet segments. These 2 scallops/segments are known to present the majority of mitral prolapses to be treated. ${ }^{11}$ In addition, A2/P2 segment allows accurate imaging. To guarantee repeatability of the measurements, all imaged hearts had to meet the following requirement: The edge of both leaflets at A2/P2, the tip of their respective anterior and posterior papillary muscle (PM), and the LV apex had to be educible on the same image in both the vertical long and the horizontal long axis. There were no relevant variations in posterior and anterior PMs.

Dedicated software (Siemens Argus Software VB13) enabled assessment of the physiologic distances between the plane of the mitral annulus at the level of leaflet coaptation of A2/P2 and the 3 different potential anchoring sites in the left ventricle for artificial chordae (Figure 1, $A$ ): the anterior PM, posterior PM, and LV apex. These 3 distances were measured in systole and diastole, and the length difference between systole and diastole was defined as $\Delta$ length anterior PM, $\Delta$ length posterior PM, and $\Delta$ length LV apex, respectively.
The potential performance of virtual neochordae was analyzed for the 3 potential anchoring sites in 2 ways (Figure 1, B). (1) In systole, the optimal chordae length was determined to achieve complete coaptation, and in diastole, the position of the proximal anchoring point and leaflet was estimated on the basis of this length. (2) In diastole, the optimal chordae length was determined to avoid leaflet tear, and then leaflet position in systole with this chordae length was estimated.

\section{Statistical Analysis}

Continuous variables are expressed as mean \pm standard deviations. Comparison among groups was performed using paired Student $t$ tests. The Statistical Package for the Social Sciences version 15.0 (SPSS Inc, Chicago, Ill) was used.

\section{RESULTS}

The length difference between systole and diastole for the 3 measured distances was $0.19 \pm 0.11 \mathrm{~cm}(5.9 \% \pm 3.4 \%)$ for the anterior PM, $0.19 \pm 0.09 \mathrm{~cm}(6.7 \% \pm 3.6 \%)$ for the posterior PM, and $1.52 \pm 0.18 \mathrm{~cm}(17.8 \% \pm 2.8 \%)$ for the LV apex. The systole/diastole length variability between the $\mathrm{PM}$ as anchoring sites and the LV apex was significant $(P=.001)$ (Figure 2).

Virtual neochordae lengths between the leaflets and the LV apex were first adjusted in systole to achieve leaflet coaptation. When the anterior leaflet was targeted in 8 of 11 volunteers $(72.7 \%)$, the artificial chorda was too short during diastole, and therefore anterior leaflet tear could occur: Too short was defined as a distance $3.5 \mathrm{~mm}$ or less from the tip of the artificial chordae to the initial anchoring site at the leaflet ( $3.5 \mathrm{~mm}$ was chosen because it is $17 \%$ [= variability of $\Delta$ length LV apex] more than the greatest $\Delta$ length to the PMs). The same phenomenon was observed in 10 of $11 \mathrm{vol}-$ unteers $(90.0 \%)$ when the posterior leaflet was targeted (Figure 1, C).

When the virtual neochordae anchored to the apex were adjusted in diastole to avoid leaflet tear, 8 of 11 artificial chordae $(72.7 \%)$ were too long during systole for both the anterior and posterior leaflets: Too long was defined as a distance $3.5 \mathrm{~mm}$ or more from the tip of the artificial chordae to the initial anchoring site at the leaflet $(3.5 \mathrm{~mm}$ was chosen because it is $17 \%$ [ = variability of $\Delta$ length LV apex] more than the greatest $\Delta$ length to the PMs). Therefore, potential residual leaflet prolapse could occur (Figure 1, C).

Furthermore, if the neochordae attached to the anterior mitral leaflet uses the apex as a ventricular anchoring site, the angle $\alpha$ (Figure 1, $A$ ) between the aortic valve plane and the mitral leaflet is significantly reduced in diastole and therefore increases the risk of systolic anterior motion.

\section{DISCUSSION}

The concept of beating heart transapical insertion of artificial chordae for mitral valve repair using the LV apex as an anchoring point for the artificial chordae has been proposed. ${ }^{9}$ This technique raises some doubts regarding the 

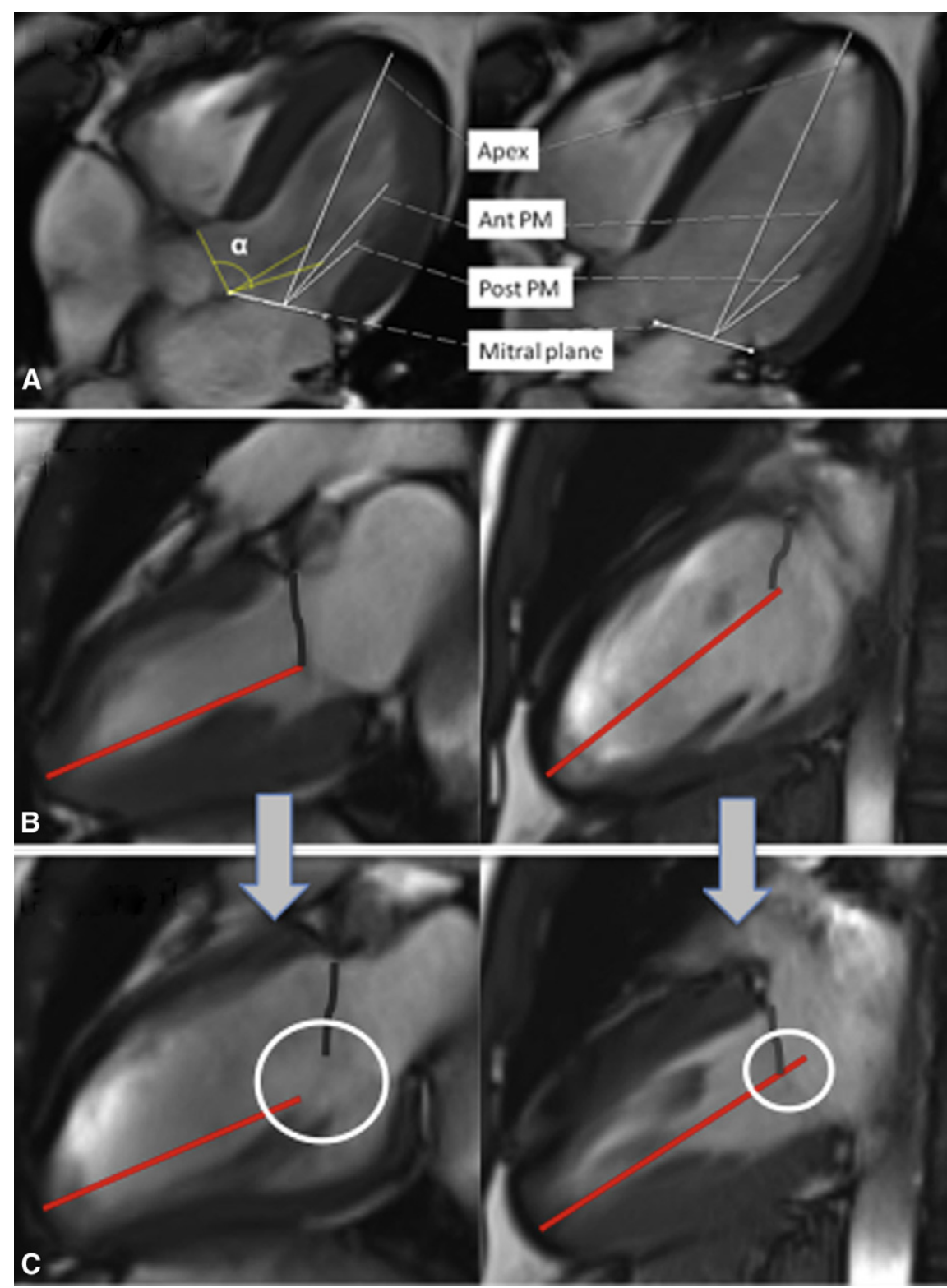

FIGURE 1. A, Three different distance measurements in systole and diastole: from the mitral annulus plane at the level of coaptation of A2/P2 to the LV apex, anterior PM, and posterior PM. The angle $\alpha$ depicts the angle between the aortic valve annulus plane and the anterior mitral valve leaflet. B, Virtual artificial chordal length adjusted in systole for optimal mitral valve coaptation or in diastole to avoid overstressing of the leaflet. C, Preadjusted virtual artificial chordal length behavior in diastole and systole. PM, Papillary muscle; ant, anterior; post, posterior; $L V$, left ventricle.

proper adjustment of the neochordae length required to obtain a perfect correction of the mitral leaflet prolapse. ${ }^{10}$

The current study proved that the systole-diastole length variation between the tip of the PMs and the mitral valve is 10 times smaller than from the LV apex to the mitral valve. Therefore, there is likely a significantly reduced risk of residual prolapse or tearing of the repaired mitral leaflet if artificial chordae are anchored to the PMs instead of to the LV apex. The contracting PMs compensate for the large motion of the LV apex toward the mitral annulus during systole. This motion comprises a long-axis length reduction of up to $17 \%$ in our healthy study individuals. Because of the simultaneous contraction of LV myocardium and PMs, the PM tips stay in place with reference to the mitral valve. If the artificial chordae are attached to the LV apex, it is the width/height of the treated leaflet or the excessive tissue of the treated prolapsing leaflet portion that determines if a too short or too long chordae can be compensated for during systole or diastole to avoid residual prolapse or tearing at the leaflet anchoring site.

The current study provides important information about motion and distance between the free margin of mitral 


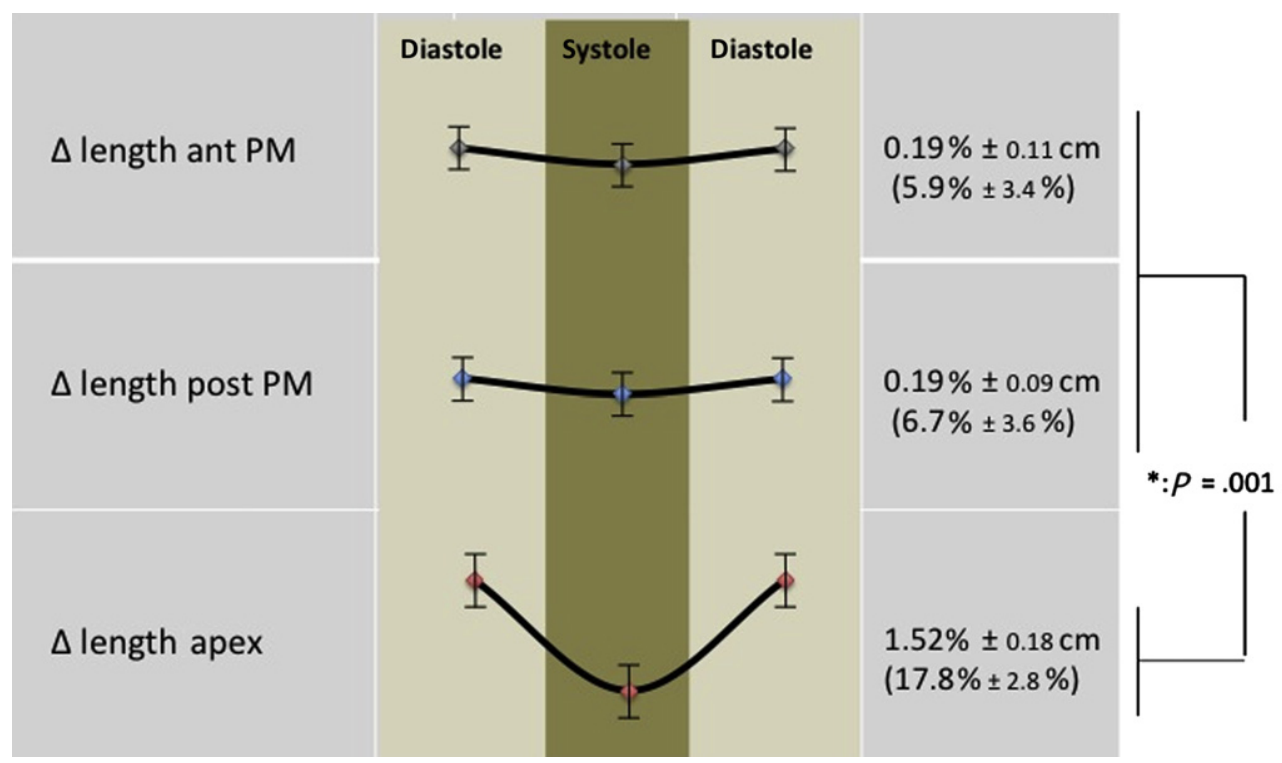

FIGURE 2. Length differences (means and standard deviations in $\%$ and $\mathrm{cm}$ ) between systole and diastole for the 3 measured distances. $\Delta$ length ant $P M$, Distance between the anterior papillary muscle and the level of mitral leaflet coaptation; $\Delta$ length post $P M$, distance between the posterior papillary muscle and the level of mitral leaflet coaptation; $\Delta$ length apex, distance between the left ventricular apex and the level of mitral leaflet coaptation.

leaflets and the tips of the PMs and the LV apex. The findings may add important input on the development of new minimally invasive devices for mitral repair, although the results must be considered with care. The results were based exclusively on dry measurements on images with virtual reconstruction, and all volunteers were healthy persons with a normal-sized left ventricle. We aimed to assess some details of the physiology of the mitral apparatus and the left ventricle and their relationship. Of course, the motions and distance relations within the left ventricle will have to be studied on dilated or hypertrophic hearts and in patients with impaired LV function and severe mitral insufficiency. These findings should be compared with patients who have undergone mitral valve repair with neochordae in further studies.

\section{CONCLUSIONS}

The ideal target sites for anchoring artificial chordae to correct mitral valve prolapse are the physiologic sites, namely, the tips of the corresponding PMs. Apical anchoring may be feasible if the mitral leaflet height/width or excessive tissue of the treated leaflet portion is sufficient to compensate the apical displacement of the heart in systole or diastole. If not, optimal length sizing of artificial chordae in systole may lead to overstretching in diastole and optimal length sizing in diastole may lead to prolapse during systole. As less-invasive approaches for repair of mitral valve prolapse are developed, percutaneous anchoring of artificial chordae at the tip of PMs should be explored.

\section{References}

1. Suri RM, Schaff HV, Dearani JA, Sundt TM 3rd, Daly RC, Mullany CJ, et al. Survival advantage and improved durability of mitral repair for leaflet prolapse subsets in the current era. Ann Thorac Surg. 2006;82:819-26.

2. Padala M, Powell SN, Croft LR, Thourani VH, Yoganathan AP, Adams DH. Mitral valve hemodynamics after repair of acute posterior leaflet prolapsed: quadrangular resection versus triangular resection versus neochordoplasty. J Thorac Cardiovasc Surg. 2009;138:309-15.

3. Vetter HO, Burack JH, Factor SM, Macuso F, Frater RW. Replacement of chordae tendineae of the mitral valve using a new expanded PTFE suture in sheep. In: Bodnar E, Yacoub M, eds. Biologic and Bioprosthetic Valves. New York: DunDonnelley Publishing; 1986. p. 772-85.

4. David TE. Replacement of chordae tendineae with expanded polytetrafluoroethylene sutures. J Card Surg. 1989;4:286-90.

5. DiBardino DJ, ElBardissi AW, McClure RS, Razo-Vasquez OA, Kelly NE, Cohn LH. Four decades of experience with mitral valve repair: analysis of differential indications, technical evolution, and long-term outcome. J Thorac Cardiovasc Surg. 2010;139:76-84.

6. Falk V, Seeburger J, Czesla M, Borger MA, Willige J, Kuntze T, et al. How does the use of polytetrafluoroethylene neochordae for posterior mitral valve prolapse (loop technique) compare with leaflet resection? A prospective randomized trial. J Thorac Cardiovasc Surg. 2008;136:1206. Epub 2008 Sep 14.

7. Salvador L, Mirone S, Bianchini R, Regesta T, Patelli F, Minniti G, et al. A 20year experience with mitral valve repair with artificial chordae in 608 patients. J Thorac Cardiovasc Surg. 2008;135:1280-7.

8. Mihaljevic T, Jarrett C, Gillinov M, Williams S, DeVilliers P, Stewart W, et al. Robotic repair of posterior mitral valve prolapse versus conventional approaches: potential realized. J Thorac Cardiovasc Surg. 2011;141:72-80.

9. Bajona P, Katz WE, Daly RC, Zehr KJ, Speziali G. Beating-heart, off-pump mitral valve repair by implantation of artificial chordae tendineae: an acute in vivo animal study. J Thorac Cardiovasc Surg. 2009;137:188-93.

10. Seeburger J, Borger MA, Tschernich H, Leontjev S, Holzhey D, Noack T, et al. Transapical beating heart mitral valve repair. Circ Cardiovasc Interv. 2010;3: 611-2.

11. Minardi G, Pino PG, Manzara CC, Pulignano G, Stefanini GG, Viceconte GN, et al. Preoperative scallop-by-scallop assessment of mitral prolapsed using 2Dtransthoracic echocardiography. Cardiovasc Ultrasound. 2010;8:1. 